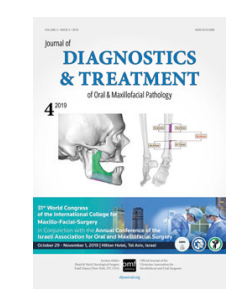

\title{
Editorial
}

\section{| Launching the YouTube Channel for DTJournal}

\author{
levgen I. Fesenko
}

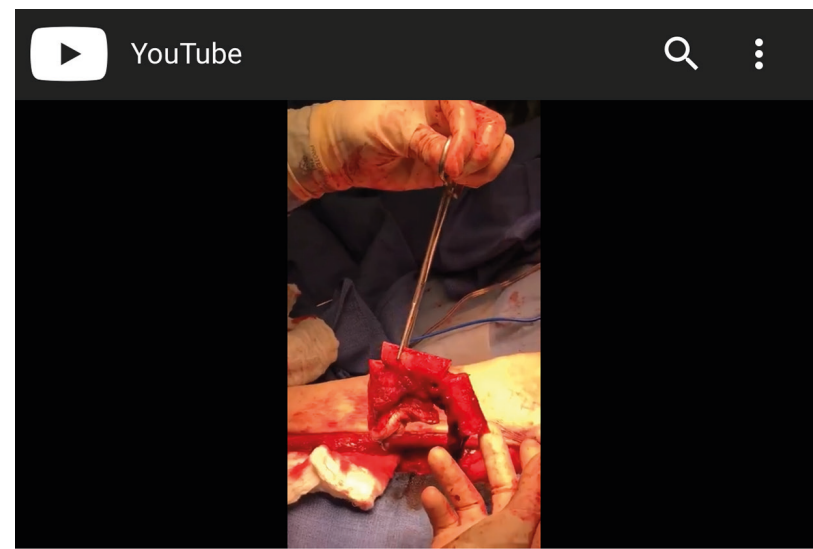

Todd Hanna, MD, DDS, FACS. Bilateral Segmental Mandibular Reconstruction. Issue 3,2019

83 views

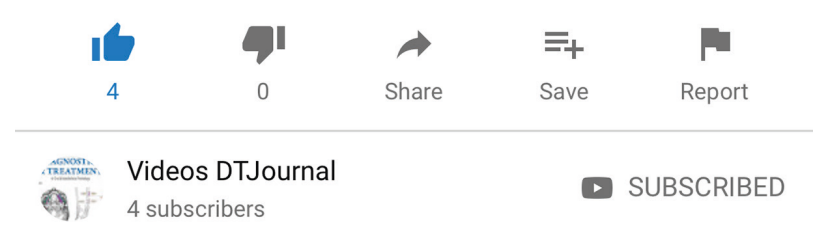

FIGURE. Videos DTJournal' an official YouTube channel of the DTJournal was launched in April, 2019.

$\mathrm{PhD}$, Assistant Professor. Department of Oral \& Maxillofacial Surgery, Private Higher Educational Establishment "Kyiv Medical University", Kyiv, Ukraine.

E-mail: i.i.fesenko@dtjournal.org (levgen Fesenko)

Instagram: dr_eugenfesenko

(C) 2019 OMF Publishing, LLC. This is an open access article under the CC BY licence (http://creativecommons.org/licenses/by-nc/4.0/) http://dx.doi.org/10.23999/j.dtomp.2019.4.1.
We started YouTube to democratize video distribution. Now, we are democratizing video creation. -Chad J. Hurley Co-founder of YouTube

Y ouTube is a free video-sharing website. It was created 14 years ago (in 2005) by three former PayPal employees-Chad Hurley, Steve Chen, and Jawed Karim.

OMF Publishing, LLC has successfully started 2 years ago its YouTube channel 'OMF Publishing LLC' for the videos linked with QR codes in the textbook. ${ }^{2}$ And for the DTJournal this is a new project. 'Videos DTJournal' is now its official YouTube channel. The first founding video (Fig) for the channel became a video case from the article of Todd Hanna and Dennis Kraus. ${ }^{3}$ And from that point, the one of the main tasks appears in front of editorial staff-to start publishing more and more cutting-edge papers with video content. With a goal to move the DTJournal forward and to move the surgery forward.

\section{REFERENCES}

1. YouTube [document on the internet]; 2019 April 28 [cited 2019 Apr 28]. Available from: https:// en.wikipedia.org/wiki/YouTube.

2. Tymofieiev OO. Clash of videos in the cutting-edge medical publications. J Diagn Treat Oral Maxillofac Pathol 2017;1:123-9. https://dx.doi.org/10.23999/j. dtomp.2017.3-4.1.

3. Hanna TC, Kraus DH. State of the art simultaneous bilateral segmental mandibular reconstruction using a single fibula transplant: discussion of the surgical steps. J Diagn Treat Oral Maxillofac Pathol 2019;3:76-103. https://dx.doi.org/10.23999/j.dtomp.2019.3.2. 